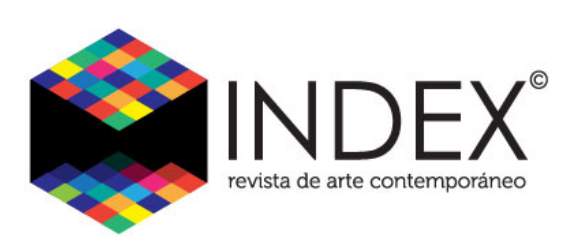

No. 12. NOV 2021

ISSN: 2477-9199

\title{
Reseñas
}

DOI: $10.26807 /$ cav.vi12.467

\section{REGISTRO ATMOSFÉRICO}

\section{ATMOSPHERIC RECORD}

Consuelo Crespo

\section{Biografía de la Autora}

Consuelo Crespo (Ecuador, 1961). Licenciada en Artes Plásticas, Escultura (Universidad

Central del Ecuador), Magíster en Estudios de la Cultura, Artes y Estudios Visuales

(Universidad Andina Simón Bolívar), Docente-investigadora (Pontificia Universidad

Católica del Ecuador). Exposición individual "El lugar de la sospecha" Galería Procesos

Ecuador, exposición colectiva "Ya no es mágico el mundo" Centro de Arte

Contemporáneo, Ecuador.

Cuán significativa es esta suspensión de toda posibilidad de hablar [...] Hay aquí un abismo, una picada temporal, un corte de la experiencia, después de la cual resulta que no tiene nada, todo terminó, no hablemos más de ello. [...] Lo que es rehusado en el orden simbólico, vuelve a surgir en lo real. 
Esta exposición propone una serie de registros tridimensionales de lo irrepresentable del sistema, de la bomba atómica, de lo real. Trabajo sobre la guerra y los abismos como aquello que no podemos aprehender y que está siempre vigente. En este escenario, la máquina aparece como un objeto omnipresente, cuyo movimiento activa el espacio y el tiempo.

La cerámica en occidente se ha concebido como un arte menor y femenino, ese es el lugar que escogí para ubicar la escultura en el margen. Cada fragmento se construye con una sucesión de movimientos donde aparece el vacío que se vuelve visible solo en la obstrucción. La forma y el material de la arcilla contrastan con la resina y sus connotaciones con el tiempo presente.

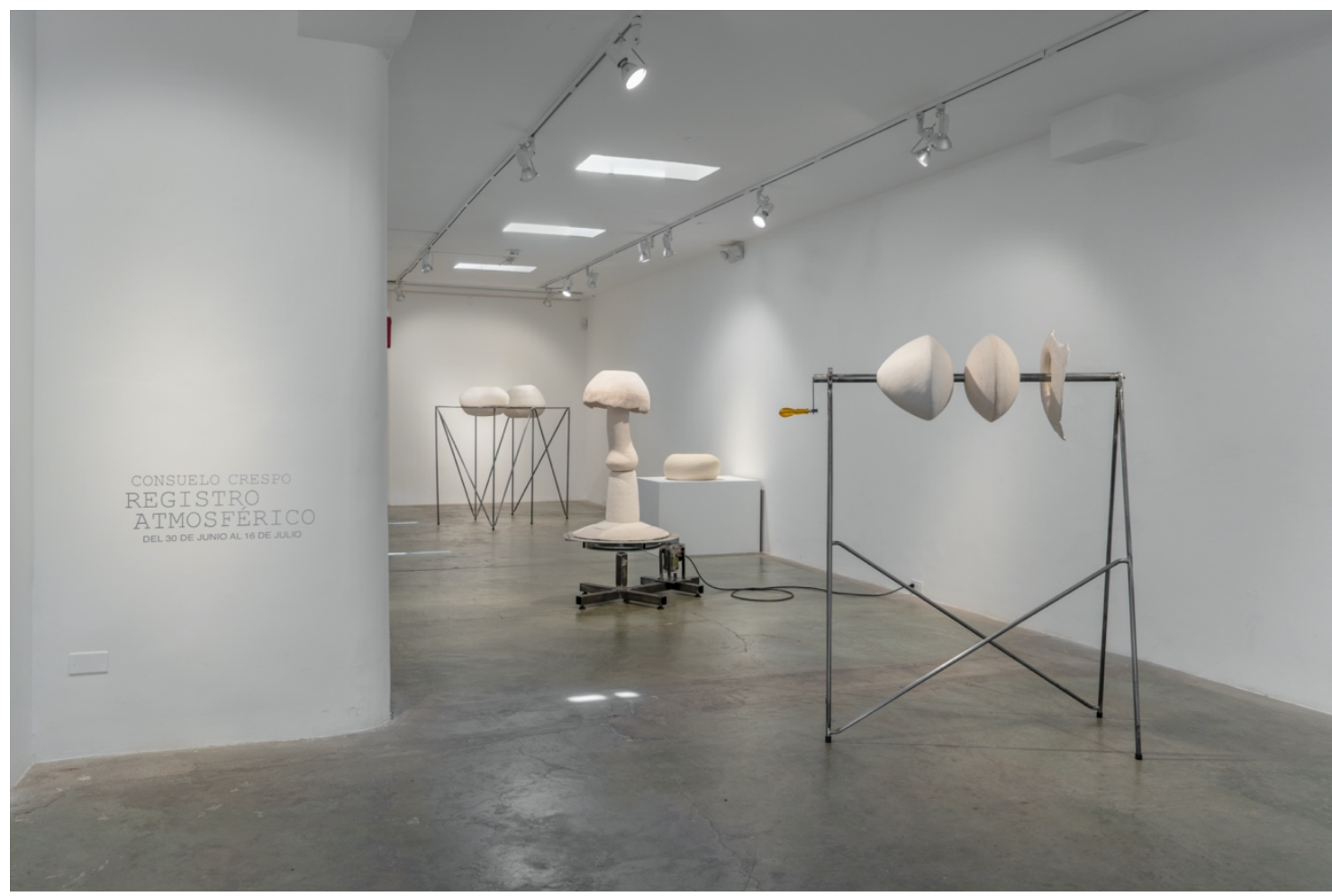

Consuelo Crespo

Vista general exhibición Registro Atmosférico, N24 Galería 
Fotografía: Alexander Alcocer, N24 Galería de Arte, 2021

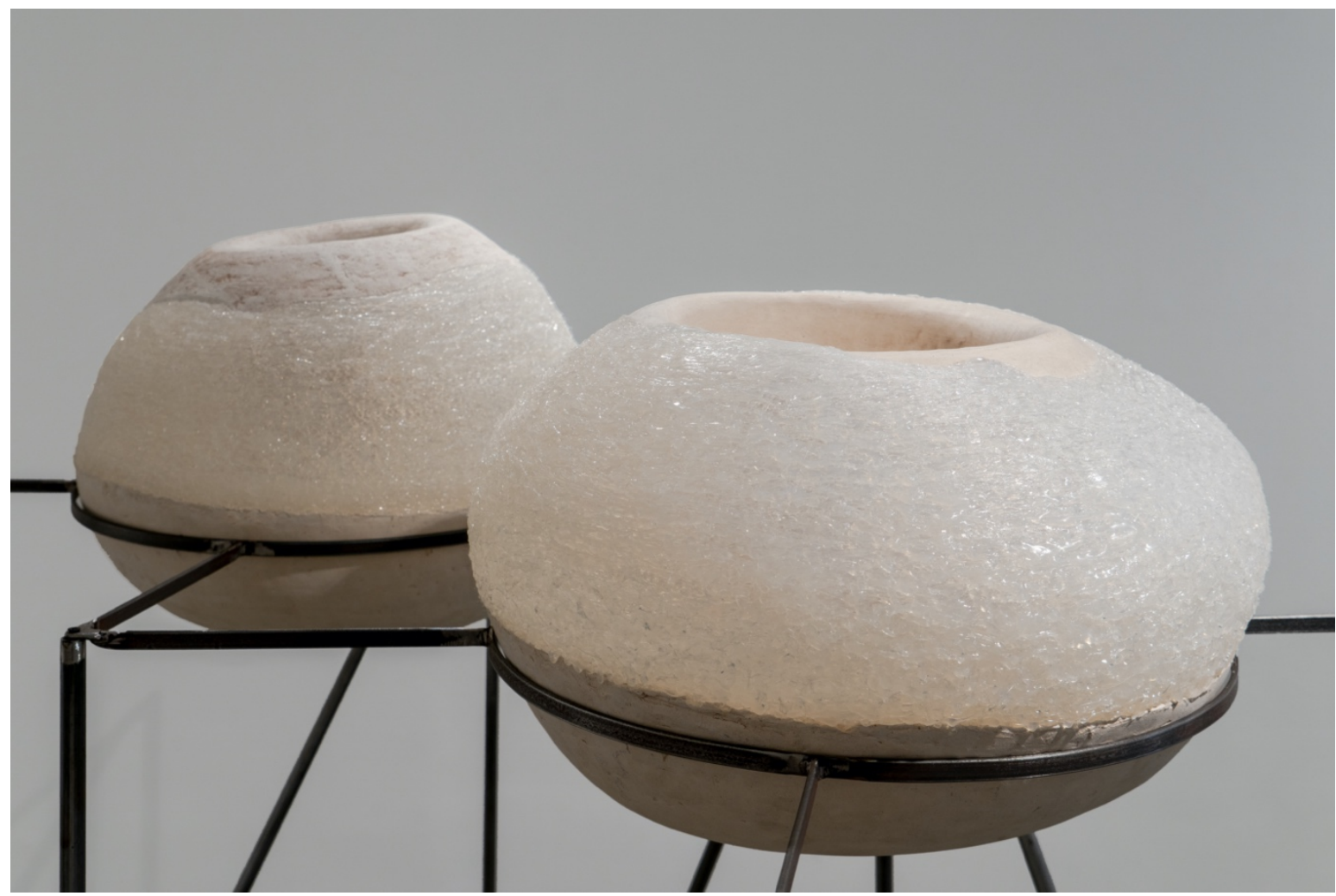

Consuelo Crespo

Registro Paralelo

Cordel, moldes de arena y hierro soldado

Diseño de mobiliario Isidro Iturralde

Medidas variables

2021

Fotografía: Alexander Alcocer, N24 Galería de Arte, 2021 


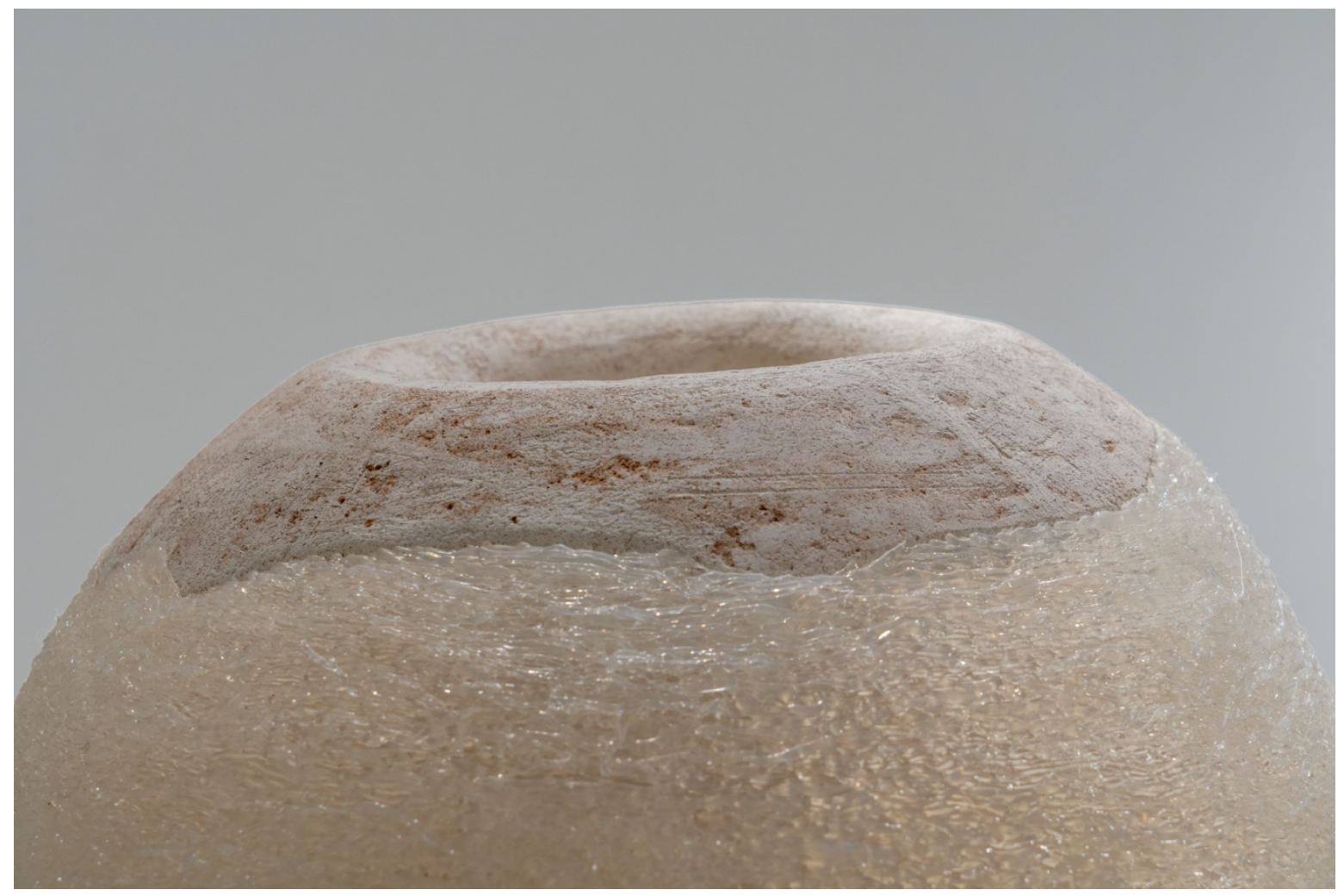

\section{Consuelo Crespo}

Registro Paralelo (Detalle)

Cordel, moldes de arena y hierro soldado

Diseño de mobiliario Isidro Iturralde

Medidas variables

2021

Fotografía: Alexander Alcocer, N24 Galería de Arte, 2021 


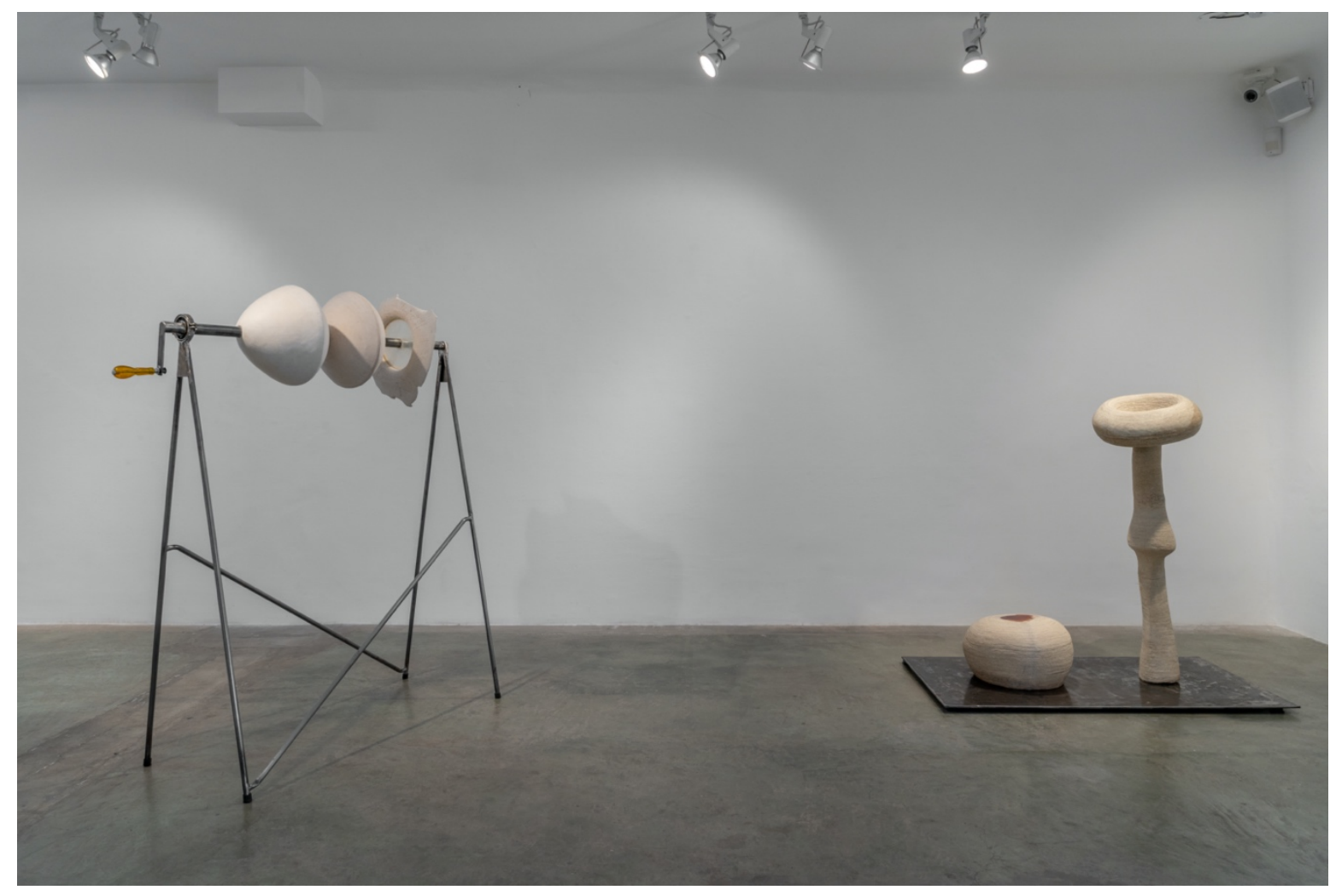

Consuelo Crespo

Vista exhibición Registro Atmosférico, N24 Galería

2021

Fotografía: Alexander Alcocer, N24 Galería de Arte, 2021 


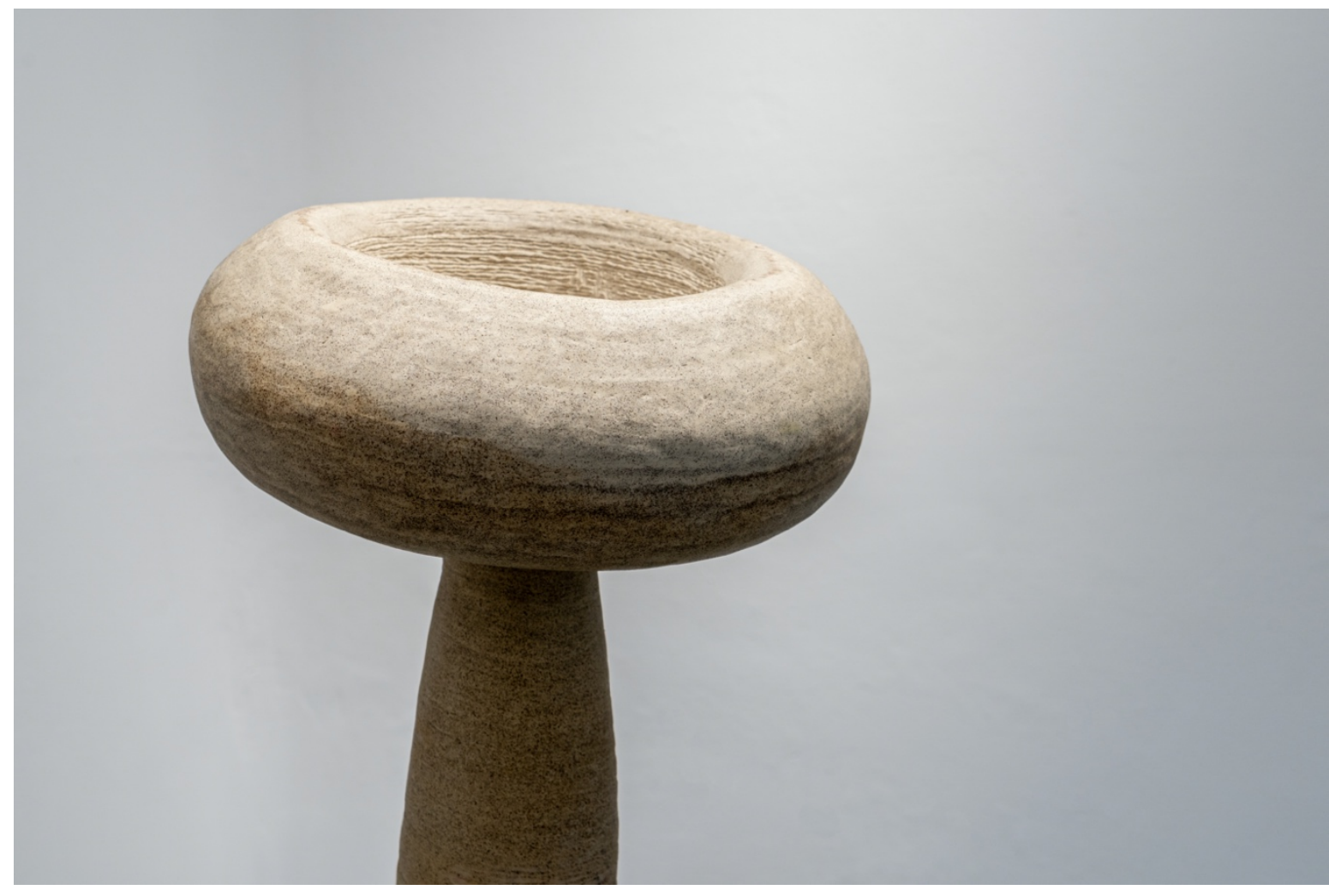

Consuelo Crespo

Registro 1 (Detalle)

Cordel, moldes de arena y hierro soldado

Medidas variables

2018

Fotografía: Alexander Alcocer, N24 Galería de Arte, 2021 


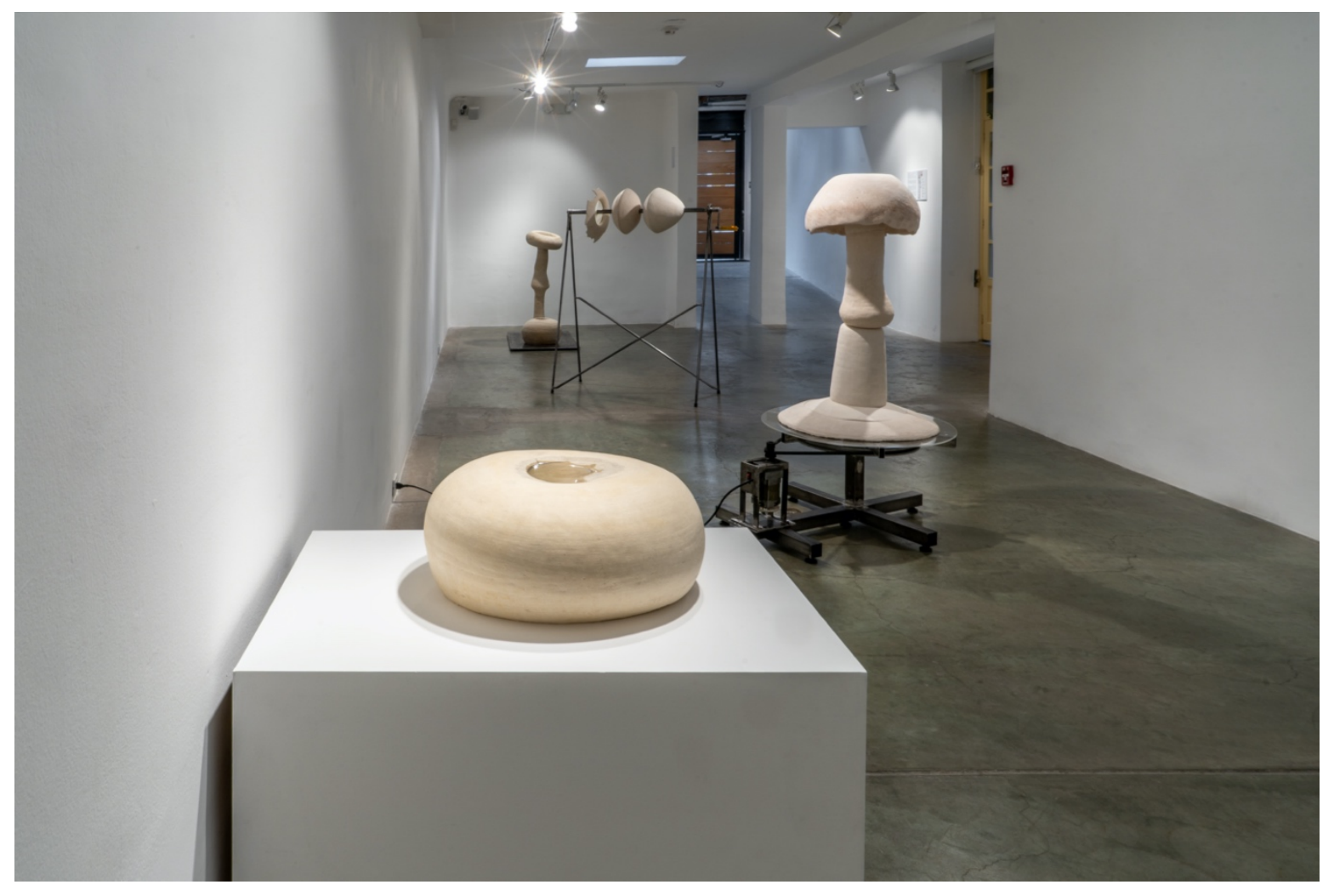

Consuelo Crespo

Vista exhibición Registro Atmosférico, N24 Galería

2021

Fotografía: Alexander Alcocer, N24 Galería de Arte, 2021 


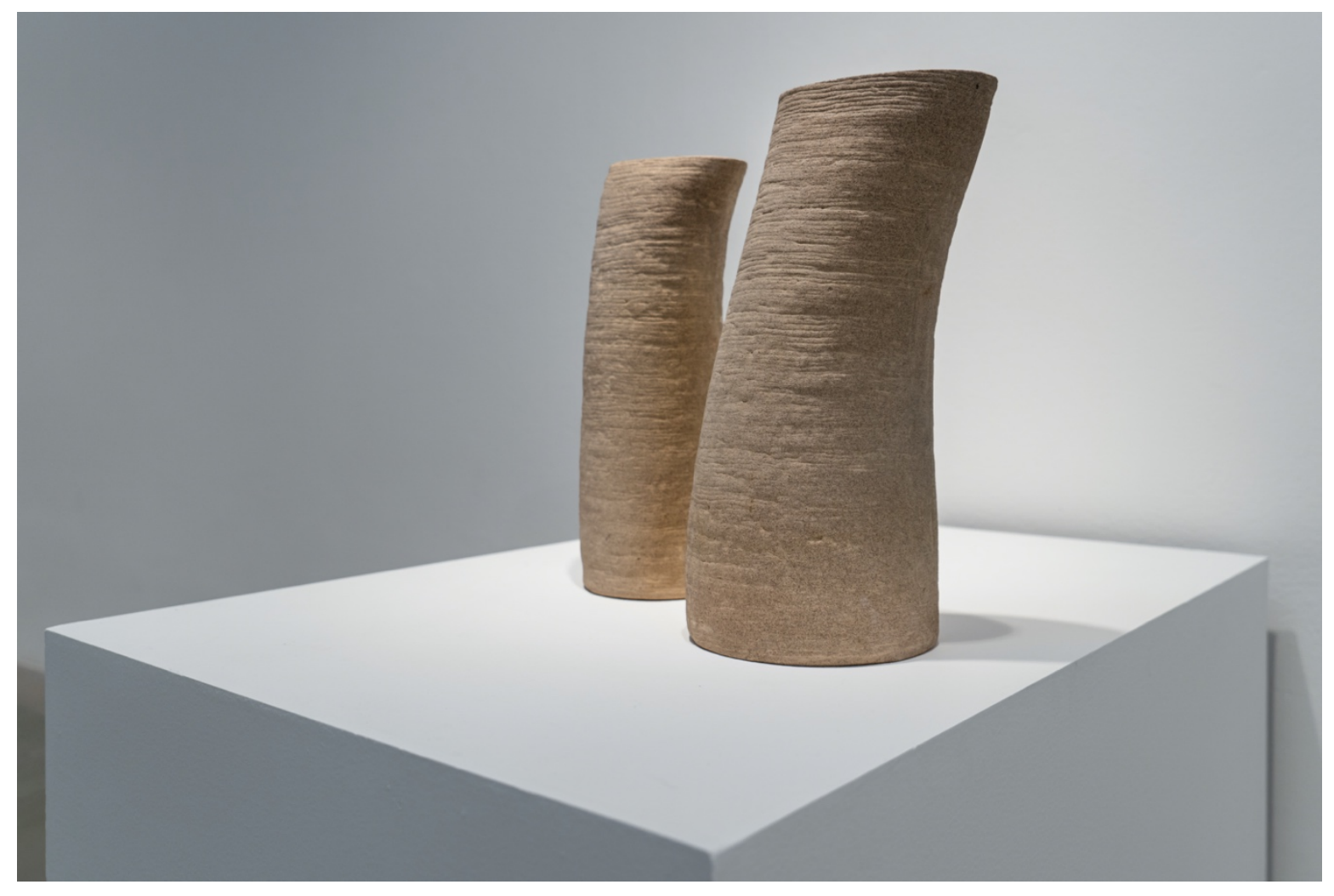

\section{Consuelo Crespo}

\section{Cilindros}

Cordel y moldes de arena

Medidas variables

2018

Fotografía: Alexander Alcocer, N24 Galería de Arte, 2021 